\title{
Children and adolescents with complex regional pain syndrome: More psychologically distressed than other children in pain?
}

\author{
Deirdre E Logan $\mathrm{PhD}^{1,2}$, Sara E Williams $\mathrm{PhD}^{1,2}$, Veronica P Carullo MD ${ }^{3}$, Robyn Lewis Claar $\mathrm{PhD}^{1,2}$, \\ Stephen Bruehl $\mathrm{PhD}^{4}$, Charles B Berde MD PhD ${ }^{1,5}$
}

\begin{abstract}
DE Logan, SE Williams, VP Carullo, RL Claar, S Bruehl, CB Berde. Children and adolescents with complex regional pain syndrome: More psychologically distressed than other children in pain? Pain Res Manag 2013;18(2):87-93
\end{abstract}

BACKGROUND: Historically, in both adult and pediatric populations, a lack of knowledge regarding complex regional pain syndrome (CRPS) and absence of clear diagnostic criteria have contributed to the view that this is a primarily psychiatric condition.

OBJECTIVE: To test the hypothesis that children with CRPS are more functionally disabled, have more pain and are more psychologically distressed than children with other pain conditions.

METHODS: A total of 101 children evaluated in a tertiary care pediatric pain clinic who met the International Association for the Study of Pain consensus diagnostic criteria for CRPS participated in the present retrospective study. Comparison groups included 103 children with abdominal pain, 291 with headache and 119 with back pain. Children and parents completed self-report questionnaires assessing disability, somatization, pain coping, depression, anxiety and school attendance.

RESULTS: Children with CRPS reported higher pain intensity and more recent onset of pain at the initial tertiary pain clinic evaluation compared with children with other chronic pain conditions. They reported greater functional disability and more somatic symptoms than children with headaches or back pain. Scores on measures of depression and anxiety were within normal limits and similar to those of children in other pain diagnostic groups.

CONCLUSIONS: As a group, clinic-referred children with CRPS may be more functionally impaired and experience more somatic symptoms compared with children with other pain conditions. However, overall psychological functioning as assessed by self-report appears to be similar to that of children with other chronic pain diagnoses. Comprehensive assessment using a biopsychosocial framework is essential to understanding and appropriately treating children with symptoms of CRPS.

Key Words: Chronic pain; Complex regional pain syndrome; Functional disability; Pediatric; Psychological functioning

\footnotetext{
$\overline{\mathrm{C}}$
} omplex regional pain syndrome (CRPS) is a neuropathic pain syndrome with autonomic features that may affect one or more extremities. Hallmarks of the syndrome include regional pain, allodynia and hyperalgesia, swelling, colour and temperature changes to the skin, and decreased range of motion or motor dysfunction (1). CRPS type I (formerly reflex sympathetic dystrophy) refers to cases in which no specific major nerve injury is identified, while type II (formerly causalgia) refers to cases with identifiable major nerve damage (2,3). Based on conservative incidence estimates, there are $>50,000$ new cases of CRPS type I in adults annually in the United States (4).

Once considered to be a rare disorder among children and adolescents, pediatric CRPS has become better recognized over the past

\author{
Les enfants et les adolescents ayant un syndrome \\ douloureux régional complexe : en plus grande \\ détresse psychologique que les autres enfants \\ ressentant des douleurs?
}

HISTORIQUE : Par le passé, au sein des populations adultes et pédiatriques, l'absence de connaissances au sujet du syndrome douloureux régional complexe (SDRC) et l'absence de critères diagnostiques clairs ont contribué à percevoir ce syndrome surtout comme un trouble psychiatrique.

OBJECTIF : Vérifier l'hypothèse selon laquelle les enfants ayant un SDRC présentent une plus grande incapacité fonctionnelle, plus de douleur et plus de détresse psychologique que les enfants ayant d'autres troubles de douleur. MÉTHODOLOGIE : Cent un enfants évalués dans une clinique de la douleur pédiatrique d'un centre de soins tertiaires qui respectaient les critères diagnostiques consensuels de l'International Association for the Study of Pain relativement au SDRC ont participé à cette étude rétrospective. Les groupes de comparaison se composaient de 103 enfants ayant des maux de ventre, de 291 enfants ayant des céphalées et de 119 ayant des douleurs dorsales. Les enfants et les parents ont rempli un questionnaire d'autoévaluation de l'incapacité, de la somatisation, de l'affrontement de la douleur, de la dépression, de l'anxiété et de la fréquentation scolaire.

RÉSULTATS : Les enfants ayant un SDRC ont déclaré une intensité de douleur plus élevée et une apparition plus récente de la douleur lors de la première évaluation à la clinique de la douleur d'un centre de soins tertiaires que les enfants ayant d'autres maladies s'associant à des douleurs chroniques. Ils ont déclaré une plus grande incapacité fonctionnelle et plus de symptômes somatiques que les enfants ayant des céphalées ou des douleurs dorsales. Les indices des mesures de dépression et d'anxiété se situaient dans les limites normales et étaient similaires à celles des enfants des autres groupes diagnostiques de douleur.

CONCLUSIONS : En tant que groupe, les enfants ayant un SDRC aiguillés vers une clinique présentent peut-être une incapacité fonctionnelle plus marquée et plus de symptômes somatiques que les enfants ayant d'autres troubles associés à la douleur. Cependant, leur fonctionnement psychologique global autoévalué semble similaire à celui des enfants ayant d'autres diagnostics de douleur chronique. Il est essentiel de procéder à des évaluations complètes faisant appel à un cadre biopsychosocial pour comprendre et traiter correctement les enfants ayant des symptômes de SDRC.

two decades (5). Compared with adults, pediatric patients with CRPS have a higher incidence of lower extremity involvement, are less likely to experience trauma preceding the onset of symptoms and are disproportionately female $(6,7)$. Although CRPS has been reported in children as young as two years of age (8), it is more common in school-age children and adolescents, with a mean age at onset of 11 to 12 years $(6,7)$.

CRPS is a complex condition best understood and treated using a biopsychosocial framework (9) in which a multitude of factors in the individual and the environment influence the course of the condition, the expression of symptoms and the course of treatment. While this framework is widely accepted, the precise contribution of psychological factors to the etiology and maintenance of pediatric CRPS

${ }^{1}$ Division of Pain Medicine, Department of Anesthesiology, Perioperative and Pain Medicine, Children's Hospital Boston; ${ }^{2}$ Department of

Psychiatry, Harvard Medical School, Boston, Massachusetts; ${ }^{3}$ Departments of Anesthesiology and Pediatrics, Montefiore Medical Center,

Albert Einstein College of Medicine, New York, New York; ${ }^{4}$ Vanderbilt University Medical Center, Department of Anesthesiology, Nashville,

Tennessee; ${ }^{5}$ Departments of Anaesthesia and Pediatrics, Harvard Medical School, Boston, Massachusetts, USA

Correspondence: Dr Deirdre E Logan, Pain Treatment Service, Children's Hospital Boston, 333 Longwood Avenue, Suite 549, Boston,

Massachusetts 02115, USA. Telephone 617-355-6694, fax 617-730-0199, e-mail deirdre.logan@childrens.harvard.edu 
remains controversial. Historically, adults with CRPS have often been viewed clinically as being more psychologically disturbed than patients with other pain conditions $(10,11)$, with a number of published case reports and small studies supporting this view and suggesting that impaired psychological functioning was a central hallmark of the disorder (12-17). However, the methodological rigour of these studies and inconsistent definitions of both CRPS and psychological dysfunction call these findings into question. Several studies have compared samples of adults with CRPS with individuals with other pain conditions in attempts to reveal a psychological profile unique to CRPS (18-20). These studies have generally failed to identify significant differences between groups. In addition to a lack of support for a central etiological role of psychological factors in more recent studies, there is also mounting evidence of multiple interacting mechanisms in the pathophysiology of CRPS, including autonomic function changes, altered somatosensory and motor processes, inflammatory mechanisms and possible genetic risk factors (21). Thus, the prevailing view of CRPS has shifted toward one of a multifaceted condition best treated using comprehensive, integrated treatment approaches $(9,11)$.

In the pediatric literature, research has not examined the role of psychological factors in CRPS as widely or systematically as in the adult literature. Clinically, however, there exist similar viewpoints and assumptions that CRPS in children may primarily represent a manifestation of psychological distress $(11,22)$. This dichotomized view of CRPS as either a biological or nonbiological (ie, psychological) entity is at odds with current, more nuanced conceptualizations of chronic pain as a biopsychosocial phenomenon, ie, an experience that is shaped by a confluence of integrated factors in biological, psychological and social realms $(23,24)$. Multiple case reports have focused on children with features of CRPS with comorbid psychiatric illness, including conversion disorder, post-traumatic stress disorder, somatization disorder and anorexia (8,25-30). A majority of these case reports implicate a psychiatric disorder as primary to the development of CRPS symptoms; however, these reports lack prospective data to support this claim, use single-subject designs, rely solely on clinical interviews and fail to apply specific diagnostic criteria when labelling patients as having CRPS. Nevertheless, these reports have served to underscore the fact that psychological distress is a hallmark of pediatric CRPS. It remains unclear whether levels of psychological distress in children with CRPS are truly elevated in comparison with children experiencing other types of chronic pain because such comparisons are absent from much of the literature.

A few studies have been published involving larger samples of children with CRPS that incorporate psychiatric clinical interviews $(6,7,31-35)$ or standardized assessments of psychological distress (22,36-39). All but one of these interview-based studies concluded that children and adolescents with CRPS had a high prevalence of elevated emotional distress compared with healthy peers and tended to be high achievers living in highstress families, citing these as factors that contribute to the syndrome (6,31-35). Conversely, results from studies using standardized assessment measures have indicated that children with CRPS routinely displayed normative levels of emotional distress, depressive symptoms, intelligence and family functioning (22,36-39). Clearly, psychological factors are important facets of the overall biopsychosocial experience of CRPS and should be thoroughly assessed and identified as targets of treatment when relevant; however, assuming that pediatric CRPS patients have a condition that is purely or primarily psychiatric runs the risk of implementing incomplete or inappropriate treatment plans.

Now that a substantial base of literature on pediatric CRPS exists, it is useful to ask questions similar to those addressed by Walker and Greene (40) in their classic comparison of children with recurrent abdominal pain to children with abdominal pain of identifiable organic etiology. Following many studies indicating that children with recurrent abdominal pain experienced elevated levels of psychological distress compared with healthy peers, Walker and Greene found similar levels of somatization, anxiety and depressive symptoms across these two abdominal pain groups, challenging long-held assumptions that nonorganic abdominal pain had a uniquely psychological component.
Inconsistencies in establishing the diagnosis of CRPS may contribute to misconceptions regarding its etiology in both adult and pediatric populations (11). The development and reliable use of specified diagnostic criteria for CRPS has been a significant issue for clinical practice and research alike $(2,3)$. Similarly, there has been a dearth of studies using standardized measurement of psychological factors. The majority of published studies rely on data drawn from clinical interviews or case studies, limiting the conclusions that can be drawn across studies. In addition, the majority of published studies involving children and adolescents with CRPS are based on small samples and lack comparison with other pediatric pain groups or with appropriate age- and sexmatched healthy controls. Comparison of psychological factors present in children with CRPS with those present in children with other chronic pain conditions would help to elucidate the association between psychological distress and pain; specifically, whether psychological factors are, in fact, more prominent in children with CRPS or whether they simply reflect the general experience of living with chronic pain.

Through a retrospective review of a large, clinically referred sample of children with well-defined CRPS, the present study sought to investigate whether children with this diagnosis had higher levels of functional disability, pain and psychological distress with reference to both normative data and to children with other pain syndromes, as has been examined recently in the adult CRPS population. The objectives of the present study were to describe patients with CRPS classified by modified International Association for the Study of Pain (IASP) criteria with respect to their demographic and pain characteristics, and to test the hypothesis that children with CRPS have more pain, functional disability and psychological distress than children with other pediatric pain conditions. Specifically, we compared standardized measures of global functional disability, somatic symptoms, depressive symptoms, anxiety symptoms, coping responses to pain and school attendance rates in children with CRPS and children with headaches, chronic abdominal pain and back pain. Because CRPS affects the extremities and involves motor dysfunction, we hypothesized that patients with CRPS would report higher levels of functional disability (both self-reported disability scores and school functioning) and more widespread somatic complaints compared with children with pain in other locations. To investigate the assertion that a psychological profile unique to CRPS exists, we tested the hypothesis that children with CRPS would manifest higher levels of anxiety and depressive symptoms and greater reliance on passive coping strategies compared with children with headache, chronic abdominal pain and back pain.

\section{METHODS}

\section{Participants}

Participants included pediatric patients (seven to 18 years of age) who underwent a multidisciplinary pain evaluation at a tertiary pain clinic in a large urban pediatric hospital (Children's Hospital, Boston, Massachusetts, USA) between January 2004 and May 2009, and who reported at least three months' duration of pain at the time of the evaluation. Children were classified into diagnostic groups based on their presenting pain complaint.

CRPS group: All patients who were evaluated for limb pain, neuropathic pain or possible CRPS were included in a retrospective chart review process to determine whether they met the modified IASP Budapest criteria for the diagnosis of CRPS, as further explained below. Children with neuropathic or limb pain who did not meet these criteria were excluded from the study. A total of 101 patients were included in the CRPS group sample.

Comparison pain groups: Children without a diagnosis of neuropathic and/or limb pain who were diagnosed with primary pain complaints of chronic abdominal pain, headache (tension, chronic daily or migraine type) or back pain were included in the study comparison groups. These comparison groups were chosen based on several factors. Headache and abdominal pain were selected because, after limb pain, they represent the most common pediatric pain problems in the general pediatric population (41). Back pain was selected because it 
represented a sizable but fairly distinct and homogenous subgroup of the chronic pain population, and because the investigators opted to include another condition with pain that was typically constant in nature, similar to CRPS (versus intermittent recurrent pain conditions such as headache and abdominal pain). The comparison groups consisted of 103 patients with abdominal pain, 291 patients with headache and 119 patients with back pain.

\section{Procedure}

The present study entailed a retrospective chart review. Approval from the hospital's institutional review board was obtained before the study was conducted. All of the questionnaires were mailed to families before the children's multidisciplinary pain clinic evaluation and were initially completed for clinical purposes. Parents and children were asked to complete the questionnaires individually and return them on the date of the evaluation. Children then underwent evaluation by a pain physician, physical therapist and clinical psychologist. Patients' primary pain diagnoses, assigned by the physician during the multidisciplinary evaluation, were obtained from a review of their medical records. Previous studies have been published using data from the larger dataset from which these participants were identified $(42,43)$; however, none focused specifically on patients with CRPS.

The process of establishing whether patients met the Budapest criteria for CRPS was conducted primarily by one physician on the research team $(\mathrm{VC})$ with assistance from the senior author $(\mathrm{CBB})$ and one other physician on the clinical team. Physicians reviewed the medical charts of all patients evaluated for limb pain or neuropathic pain and classified children according to the Budapest criteria for CRPS $(2,3)$ (Table 1). All children meeting the Budapest criteria also met the less stringent current IASP diagnostic criteria for CRPS. The Budapest criteria have been found to be valid and accurate for the classification of adult patients with CRPS for research and clinical purposes (44). No separate diagnostic criteria have been developed specifically for pediatric populations. The adult classification system includes a set of criteria for establishing the diagnosis for research purposes and a similar set of criteria with slightly less stringent decision rules for clinical diagnosis. Because the adult-based research criteria may be overly stringent when applied to children, the 'clinical' threshold was used for establishing the diagnosis of CRPS via the Budapest criteria.

\section{Measures}

Pain rating: As part of the semistructured interview with the clinical psychologist, children were asked to provide their current pain rating at rest on a standard 11-point numerical rating scale (NRS) from 0 (no pain) to 10 (most pain possible). The NRS has been demonstrated to be a reliable and valid tool for assessing pain intensity (45). Basic demographic and pain information: On the pain treatment service information form, parents provided basic demographic data (eg, child's age, sex, parents' occupations, education, marital status, number of children in the family) and pain information (pain duration, past treatments sought for pain and chronic pain in other family members). They also reported on the child's school attendance, defined as the number of school days missed in the most recent three months of school (with a possible range of 0 to 60 , given approximately 20 school days per month).

Functional Disability Inventory: The Functional Disability Inventory (FDI) $(46,47)$ is completed by children and assesses their self-reported difficulty in physical and psychosocial functioning due to their physical health. The instrument consists of 15 items concerning perceptions of activity limitations during the past two weeks; total scores are computed by summing the items. Higher scores indicate greater disability. The FDI has demonstrated good reliability and validity in pediatric populations.

Children's Somatization Inventory: The Children's Somatization Inventory (CSI) (48) is completed by children and assesses the severity of their nonspecific somatic symptoms (eg, 'weakness', 'dizziness') that need not have organic disease etiology. Respondents rate the extent to which they have experienced each of 35 symptoms during

\section{TABLE 1}

\section{Modified IASP criteria for classifying CRPS for research and clinical purposes}

To make the clinical diagnosis of CRPS, the following criteria must be met:

1. Continuing pain that is disproportionate to any inciting event

2. Patient must report one symptom by history in three of the four symptom categories:

a. Sensory: Reports of hyperesthesia and/or allodynia

b. Vasomotor: Reports of temperature asymmetry and/or skin colour changes and/or asymmetry

c. Sudomotor/edema: Reports of edema and/or sweating changes and/or asymmetry

d. Motor/trophic: Reports of decreased range of motion and/or motor dysfunction (weakness, tremor, dystonia) and/or trophic changes (hair, nail, skin)

3. Must display at least one sign at the time of evaluation in two or more sign categories:

a. Sensory: Evidence of hyperalgesia (to pinprick) and/or allodynia (to light touch, temperature sensation, deep somatic pressure and/or joint movement)

b. Vasomotor: Evidence of temperature asymmetry and/or skin colour changes and/or asymmetry

c. Sudomotor/edema: Evidence of edema and/or sweating changes and/ or asymmetry

d. Motor/trophic: Evidence of decreased range of motion and/or motor dysfunction (weakness, tremor, dystonia) and/or trophic changes (hair, nail, skin)

4. There is no other diagnosis that better explains the signs and symptoms For research purposes, the diagnostic decision rule is at least one symptom in all four symptom categories by history and at least one sign in two or more sign categories observed on evaluation

CRPS Complex regional pain syndrome; IASP International Association for the Study of Pain. Adapted from Harden et al (3)

the previous two weeks using a five-point scale ranging from 0 ('not at all') to 4 ('a whole lot'). Higher scores indicate higher levels of somatic symptoms; total scores are computed by summing the items. The CSI has been found to have good reliability and validity in pediatric populations (48).

The Children's Depression Inventory: Depressive symptoms were assessed using the Children's Depression Inventory (CDI) $(49,50)$. The CDI contains 27 child self-report items representing depressive symptoms. Items are rated on a three-point scale, summed to obtain a total score, then converted to standardized (T) scores with a mean of 50 and SD of 10. Higher scores indicate higher levels of depressive symptoms. The CDI has been found to have good reliability and validity for children seven to 17 years of age.

Revised Children's Manifest Anxiety Scale: The Revised Children's Manifest Anxiety Scale (RCMAS) (51) is a 37-item child self-report questionnaire that assesses symptoms of anxiety. Total anxiety scores are calculated by summing all items, with the exception of the lie scale items. Summed scores are then converted to $\mathrm{T}$ scores with mean of 50 and SD of 10. The RCMAS is a well-validated and reliable measure of anxiety for children seven to 17 years of age.

Pain Response Inventory: The Pain Response Inventory (PRI) assesses children's typical coping strategies during pain episodes (52). The PRI consists of three scales; the 15-item Passive Coping Scale was used in the present study. Children respond to the stem "When I have pain, I . . ." followed by statements reflecting passive and avoidant coping strategies, including catastrophizing (eg, "Think it's never going to stop"), isolation (eg, "Go off by yourself") and disengagement (eg, "Think to yourself that there's nothing you can do, so you don't even try?"). Response categories range from 0 ('never') to 4 ('always'); responses are summed to create total scores that can range from 0 to 60 . Items are coded so that higher scores reflect more frequent passive pain coping. Because it was added to the assessment battery at a later time point, the PRI was only completed by $51 \%$ of the total sample $(n=314)$. 
TABLE 2

Comparison of demographic and pain characteristics between pain groups*

\begin{tabular}{|c|c|c|c|c|}
\hline & $\begin{array}{l}\text { CRPS } \\
(n=101)\end{array}$ & $\begin{array}{l}\text { Headache } \\
(n=291)\end{array}$ & $\begin{array}{l}\text { Abdominal } \\
\text { pain }(n=103)\end{array}$ & $\begin{array}{l}\text { Back pain } \\
(n=119)\end{array}$ \\
\hline \multicolumn{5}{|l|}{ Sex, \% } \\
\hline Male & 14.9 & 32.3 & 29.1 & 24.8 \\
\hline Female & 85.1 & 67.7 & 70.9 & 75.2 \\
\hline \multicolumn{5}{|l|}{ Parent marital status, $\%$} \\
\hline Married & 83.2 & 75.6 & 76.7 & 63 \\
\hline Not married & 16.8 & 24.4 & 23.3 & 37 \\
\hline \multicolumn{5}{|l|}{ Ethnicity, \% } \\
\hline Caucasian & 93.1 & 88.7 & 87.4 & 84 \\
\hline Noncaucasian & 6.9 & 11.3 & 12.6 & 16 \\
\hline Age, years & $13.41 \pm 0.24$ & $13.58 \pm 0.14$ & $13.67 \pm 0.24$ & $14.85 \pm 0.22$ \\
\hline Number of siblings & $1.75 \pm 0.11$ & $1.63 \pm 0.06$ & $1.60 \pm 0.11$ & $1.65 \pm 0.10$ \\
\hline $\begin{array}{l}\text { Mother's education, } \\
\text { years }\end{array}$ & $15.52 \pm 0.25$ & $15.34 \pm 0.15$ & $15.19 \pm 0.25$ & $14.56 \pm 0.23$ \\
\hline $\begin{array}{l}\text { Father's education, } \\
\text { years }\end{array}$ & $15.79 \pm 0.30$ & $15.50 \pm 0.18$ & $15.75 \pm 0.30$ & $14.70 \pm 0.28$ \\
\hline Pain duration, months & $13.00 \pm 2.9$ & $32.60 \pm 1.7$ & $28.14 \pm 2.9$ & $23.25 \pm 2.7$ \\
\hline Current pain intensity & $6.39 \pm 0.28$ & $3.25 \pm 0.17$ & $3.55 \pm 0.28$ & $5.06 \pm 0.26$ \\
\hline $\begin{array}{l}\text { Family history of chronic } \\
\text { pain, } \% \text { positive }\end{array}$ & 61 & 70 & 72.5 & 73.5 \\
\hline $\begin{array}{l}\text { Previous psychological/ } \\
\text { behavioural pain } \\
\text { treatment, \% positive }\end{array}$ & 21 & 24 & 44 & 18.5 \\
\hline
\end{tabular}

Data presented as mean \pm SE unless otherwise indicated. *Percentage of participants per category presented for categorical variables; means $\pm S E$ presented for continuous variables. CRPS Complex regional pain syndrome

The percentage of completed PRI data for each pain group ranged from $43.4 \%$ of the headache group to $61.5 \%$ of the abdominal pain group (with 51\% complete PRI data available in both the CRPS and back pain groups). The PRI has demonstrated reliability and validity for children and adolescents.

\section{Data analysis}

Data analyses consisted of comparisons between the CRPS group and the headache, abdominal pain and back pain groups combined, as well as individually. To examine descriptive variables between groups, categorical outcome variables were analyzed using $\chi^{2}$ tests and continuous outcome variables were analyzed using one-way ANOVAs. To examine psychological and physical functioning variables between groups, these variables were analyzed using one-way ANOVAs followed by post hoc least significant difference tests between the CRPS group and each of the other pain groups. Demographic and pain-related variables that differed significantly between the CRPS group and other pain groups were included as covariates in the model if they also correlated significantly with the dependent variable. Effect sizes are reported as Cohen's d for tests of mean differences and ANOVAs $(\mathrm{d}<0.2=$ small, $\mathrm{d}<0.5=$ medium, $\mathrm{d}<0.8=$ large). The $\mathrm{w}$ statistic indicates effect size in $\chi^{2}$ analyses, wherein $\mathrm{w}=0.1$ is a small effect, $w=0.3$ is a medium effect and $w=0.5$ is a large effect (53).

\section{RESULTS}

\section{Preliminary analyses}

All data were examined to ensure that they met assumptions of normality and were suitable for parametric statistical analyses. All variables met these criteria with the exception of number of school absences, which was not normally distributed and was subsequently analyzed with nonparametric statistical tests. Among children with CRPS, the vast majority (77.2\%) were affected in one or both lower extremities (29.7\% in the right leg, 38.6\% in the left leg, 8.9\% in both legs). Upper extremity CRPS pain was far less common $(7.9 \%$ in the right arm, $5.9 \%$ in the left arm). Four per cent of children reported
CRPS pain in both one upper and one lower extremity, and 5\% reported pain in more than two extremities.

Differences in demographic and pain characteristics between groups Comparing demographic and pain characteristics of the CRPS group with the other pain groups yielded a number of statistically significant distinctions (means and frequencies according to pain group are presented in Table 2$)$. The CRPS group was more predominantly female $\left(\chi^{2}=9.10, \mathrm{df}=1 ; \mathrm{P}<0.01\right.$; effect size $\left.\mathrm{w}=0.25\right)$ compared with the combined other pain groups. Parents of CRPS patients were more likely to be married $\left(\chi^{2}=4.96, \mathrm{df}=1 ; \mathrm{P}<0.05 ; \mathrm{w}=0.18\right)$ than parents of children in all other pain groups. Several differences emerged between the CRPS group and the back pain group that did not differ when children with CRPS were compared with children with headache or abdominal pain. Children with back pain were significantly older than children with CRPS ( $t=5.47, \mathrm{df}=218 ; \mathrm{P}<0.001 ; \mathrm{d}=6.26$ ). A higher proportion of children with CRPS were Caucasian compared with the back pain group $\left(\chi^{2}=4.56, \mathrm{df}=1 ; \mathrm{P}<0.05 ; \mathrm{w}=0.18\right)$. Finally, mothers of children with CRPS had significantly more education than mothers of children with back pain $(t=2.93, \mathrm{df}=210 ; \mathrm{P}<0.01 ; \mathrm{d}=4.0)$.

With regard to pain characteristics, children with CRPS had shorter duration of pain on initial presentation to a multidisciplinary chronic pain clinic compared with individuals from all other pain groups $(\mathrm{F}[3,602]=12.23 ; \mathrm{P}<0.001 ; \mathrm{d}=0.29)$. Controlling for the effects of sex on pain intensity, children with CRPS had higher current ratings of resting pain severity compared with children in all other pain groups $(\mathrm{F}[3,600]=32.94 ; \mathrm{P}<0.001 ; \mathrm{d}=0.49)$; there were no differences among pain groups on ratings of highest pain severity. The pain groups did not differ with regard to family history of chronic pain.

Compared with children with abdominal pain, children with CRPS were less likely to have used psychological treatment methods to address their pain problems $\left(\chi^{2}=12.58, \mathrm{df}=1 ; \mathrm{P}<0.001 ; \mathrm{w}=0.63\right)$. They were more likely than children in the combined other pain groups to have used physical therapy $\left(\chi^{2}=100.9, \mathrm{df}=1 ; \mathrm{P}<0.001 ; \mathrm{w}=0.90\right)$ and nerve blocks $\left(\chi^{2}=53.39, \mathrm{df}=1 ; \mathrm{P}<0.001 ; \mathrm{w}=0.63\right)$. There were no group differences in reported rates of using acupuncture for pain treatment.

\section{Psychological and physical functioning}

The CRPS group was compared with other pain groups on measures of functional disability (scores on FDI and school attendance rates) and psychological functioning (scores on CSI, CDI, RCMAS and PRI). Of the demographic variables that differed among pain groups, those that correlated with the outcome variable for each individual analysis as listed above were included. Pain duration did not correlate with any outcomes of interest and was, therefore, not included in the analyses. Figures 1 and 2 present means and statistical differences between the CRPS group and comparison pain groups for each of the functional and psychological outcome variables. Regarding the functional outcomes (FDI scores and school attendance), there was a significant effect of pain diagnostic group (ie, 'group') on global physical functioning ( $\mathrm{F}[3,551]=5.08$; $\mathrm{P}<0.01 ; \mathrm{d}=0.19$ ). Post hoc least significant difference comparisons revealed that the CRPS group reported more functional impairments on the FDI than children with headache $(\mathrm{P}<0.001)$ and back pain $(\mathrm{P}<0.001)$. School absence rates, analyzed using the Kruskal-Wallis test, also differed significantly across pain groups $\left(\chi^{2}=37.38, \mathrm{df}=3 ; \mathrm{P}<0.001\right.$; $\mathrm{w}=0.52)$. This omnibus test was followed by Mann-Whitney $U$ comparisons of the CRPS group with each other pain diagnostic group. These two-group comparisons revealed that children in the CRPS group missed significantly less school than children with headaches $(Z=-2.10$; $\mathrm{P}<0.05)$ and children with abdominal pain $(Z=-5.02 ; \mathrm{P}<0.001)$. No significant difference in school attendance rates emerged between children with CRPS and children with back pain.

In terms of psychological functioning, children with CRPS were first compared with normative data on the CDI and RCMAS, the measures for which published normative comparison data exist. The mean CDI T score for the CRPS sample was well within the normative range for depressive symptoms. The percentages of the CRPS group in the at-risk ( $T$ score $\geq 60$ ) and clinically significant ( $T$ score $\geq 65$ ) ranges 


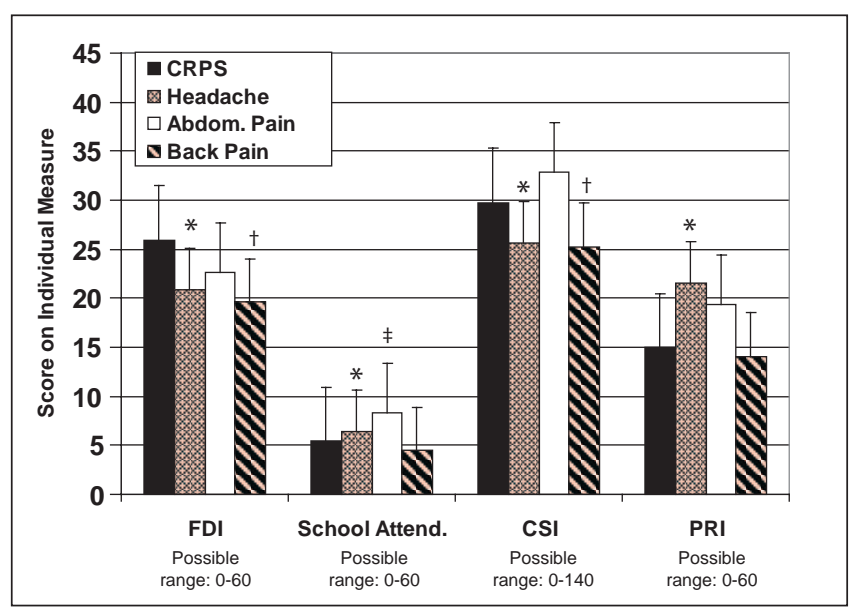

Figure 1) Mean \pm SEM and tests of significant differences between the complex regional pain syndrome (CRPS) group and comparison pain diagnostic groups on Functional Disability Inventory (FDI), school attendance (Attend.), Child Somatization Inventory (CSI) and Pain Response Inventory (PRI) total scores. *CRPS group significantly different from headache group; ${ }^{\dagger} \mathrm{CRPS}$ group significantly different from back pain group; ${ }^{\ddagger}$ CRPS group significantly different from abdominal (Abdom.) pain group

for depressive symptoms were $15.8 \%$ and $13.7 \%$, respectively. In the normative sample of 13 - to 17 -year-old females, a T score of 60 represents the $83 \mathrm{rd}$ percentile and a T score of 65 represents the $93 \mathrm{rd}$ percentile (49). The mean ( \pm SD) RCMAS T score for the CRPS group was $47.3 \pm 11.8$, well within the normal range. The percentage of youth with CRPS who were 'at risk' for anxiety was $15.2 \%$. Only $6.5 \%$ of the CRPS sample scored in the clinically significant range ( $T$ score $\geq 65$ ) on this measure. These percentages are similar to those from the normative comparison sample. For example, in the RCMAS normative sample of 14-year-old girls, a T-score of 65 represents the 95th percentile (51).

Regarding comparisons of psychological functioning between the pain groups, there was a significant effect of pain group on somatization ( $\mathrm{F}[3$, $500]=6.20 ; \mathrm{P}<0.001 ; \mathrm{d}=0.22$ ). Post hoc comparisons revealed that children with CRPS reported more somatic symptoms on the CSI (eg, difficulty walking, pains in the arms or legs, weakness, numbness or tingling, pains in the joints) than children with headache and back pain; there were no significant differences on the CSI between CRPS and abdominal pain groups. The effect of group on depressive symptoms demonstrated only a trend toward statistical significance $(\mathrm{F}[3,547]=2.19 ; \mathrm{P}<0.088$; $\mathrm{d}=0.13$ ); therefore, post hoc comparisons were not pursued. There were no significant differences between children with CRPS and any of the comparison groups on the anxiety measure. There was a significant effect of group on passive pain coping scores $(\mathrm{F}[3,288]=5.75 ; \mathrm{P}<0.01 ; \mathrm{d}=0.28)$. Post hoc comparisons revealed that children with CRPS reported significantly less passive coping on the PRI than children with headaches; there were no significant differences in passive pain coping between children with CRPS and children with abdominal or back pain.

\section{DISCUSSION}

The present study sought to describe a sample of children diagnosed with CRPS using well-validated and accepted diagnostic criteria and to compare this sample with children with other pain conditions in terms of demographic, pain, physical functioning and psychological characteristics using standardized, validated measures. Results reveal that the vast majority of children with CRPS are female, with an even greater sex disparity in this diagnostic group compared with other pediatric chronic pain conditions. The previously documented lower extremity preponderance in pediatric CRPS $(6,7)$ was confirmed in the present study. Relative to other chronic pain conditions seen at our tertiary care pediatric pain clinic, children with CRPS have shorter mean pain duration at the time of referral to a tertiary care pain clinic and report higher

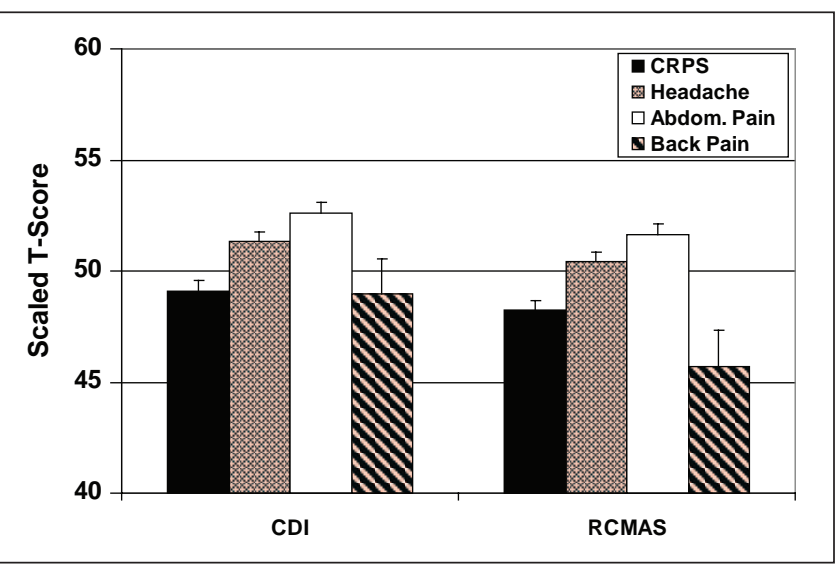

Figure 2) Mean ( \pm SEM) and tests of significant differences between the complex regional pain syndrome (CRPS) group and comparison pain diagnostic groups on Children's Depression Inventory (CDI) and Revised Child Manifest Anxiety Scale (RCMAS) standardized (T) scores. No significant differences were observed between the CRPS group and any comparison pain diagnostic group. Abdom. Abdominal

current pain severity. It is notable, however, that all groups in the present study had a mean pain duration of $>1$ year at the time of evaluation in this clinic, underscoring both the complexity of this sample and the use of tertiary pediatric chronic pain clinics as a 'last resort' referral after failure to improve with more standard routes of care.

Children with CRPS are more likely to have tried physical therapy and anesthetic block procedures before their initial multidisciplinary evaluation than children with other pain conditions, but are less likely to have pursued psychological treatment compared with children with abdominal pain. It is possible that the longer time since pain onset for the abdominal pain group compared with the CRPS group accounts for their increased previous exposure to psychological treatment. The difference in current reported pain severity between the CRPS group and other diagnostic groups is particularly striking, given that ratings were taken at rest and CRPS pain is exacerbated by touch and movement.

Partially confirming the study hypotheses, differences between CRPS and other pain conditions were noted in levels of pain-related disability, with the CRPS group reporting more global functional disability than the other diagnostic groups. Similarly, these children reported more widespread pain and other symptom complaints on the CSI. Because pediatric CRPS typically involves a lower extremity, thus inhibiting ambulation, it is not surprising that daily functional abilities are more impaired in this group. The greater number of somatic symptoms may be accounted for by the fact that CRPS is considered to entail central pain sensitization and thus may lead to pain and hyperesthesia in other areas of the body over time. However, the alternative explanation, that children with CRPS have heightened levels of hypervigilance to physiological or somatic experiences, cannot be ruled out and merits further investigation (54).

In terms of school attendance, the opposite pattern emerged. Children with CRPS reported fewer missed school days than children with headache or abdominal pain, suggesting that even in the face of greater physical disability, children with CRPS as a group report comparatively less school impairment. This is somewhat surprising because CRPS is typically characterized by constant pain whereas headache and abdominal pain may be intermittent. Perhaps some children with constant pain find ways to function in spite of their ongoing pain, whereas children with episodic pain are more debilitated by their pain episodes. More research is required in this area to understand these patterns.

Contrary to the hypothesis, at the group level, children with CRPS reported no greater anxiety or depressive symptoms than children with other pain conditions, with self-reported symptoms within normal limits compared with standardized scores based on normative samples. In some respects, the CRPS group appears to be less psychologically impaired than children with other types of chronic pain. Relative to 
other diagnostic groups in the sample, the CRPS group was less likely to use passive coping strategies (eg, pain catastrophizing), which have been demonstrated to be less effective ways of coping with pain $(42,52)$. The finding that these children, on average, do not manifest clinically significant psychological distress is consistent with previous research of children with CRPS using standardized assessment tools (36), and in opposition to studies relying solely on interview and case study methodologies that report elevated levels of psychological impairment $(25,31)$. It is clear that group means do not capture the individual variation that undoubtedly exists within the pediatric CRPS population. Clinical experience suggests that some children with CRPS do, in fact, present with elevated symptoms of depression and anxiety, similar to children with other chronic pain conditions, whereas other children may demonstrate psychological resilience in the face of the challenges of chronic pain. In the setting of a chronic pain clinic where children present with a mean pain duration of one to two years, it is not possible to determine whether this distress, when present, is a cause or consequence of the pain experience, or simply a coexisting condition. However, these group-level findings provide an important balance against previous case studies and clinical observations that imply a primarily psychological etiology in patients with CRPS. It should be noted that the absence of significant psychological differences between pediatric CRPS patients and patients with other chronic pain conditions in the present study can be interpreted with more confidence than in previous studies due to the relatively large sample size available and the application of rigorous CRPS diagnostic criteria. The current study would have been able to detect a difference between CRPS patients and other pain groups reflecting even a small to moderate effect size $(d=0.40)$ with a statistical power of 0.80 if such differences existed.

Recent work involving adult CRPS patients suggests that the role of psychological factors in the condition may be linked to physiological processes (55). Although results of the current study indicate that children with CRPS may not experience a unique degree of psychological distress compared with children with other chronic pain conditions, this does not necessarily rule out a possible impact of emotional distress on CRPS development, potentially via links between distress and adrenergic mechanisms contributing to CRPS (55). For example, Harden et al (2) found that in adults, greater increases in anxiety and depression in the four weeks following total knee arthroplasty predicted greater levels of CRPS symptoms up to 12 months following surgery. In a daily diary study of adults with CRPS, Feldman et al (56) suggest that a transactional relationship exists among pain, emotional distress and social support, such that pain and emotional distress (depression, anger, anxiety) exacerbate one another, with social support exerting a protective buffering influence. In a study of brain anatomy using magnetic resonance imaging techniques, Geha et al (57) detected abnormal gray-white matter interactions that could account for both pain and emotional reactions in adults with CRPS. Collectively, these studies suggest that psychological factors are frequently involved in the experience of CRPS among adult patients; however, their role is likely to be complex and is not yet fully understood. Clearly, more research is needed to understand these associations in the pediatric population.

Overall, the findings of the present study support the view that pediatric CRPS is a complex condition that can be best understood and treated through a biopsychosocial framework. These results do not support assertions in some previous reports that the psychological aspects of CRPS are more pronounced than those of other chronic pediatric pain disorders. Many children presenting for tertiary evaluation of CRPS report having previously been told that the condition is due to stress, or is 'all in their heads'. While it is likely that psychological factors in the child and family do influence the expression of CRPS in terms of its course, severity and/or response to treatment, assuming that children fit a particular personality type or have significant psychiatric involvement in the presentation of their pain condition based on a CRPS diagnosis alone is unfounded and may be detrimental to children and their families seeking to understand an often difficult and confusing diagnosis. Certainly, the identification and treatment of psychological concomitants, such as symptoms of depression or anxiety, and of interpersonal factors that can influence the course of the disorder, such as family dynamics and parental responses to pain behaviours, are important goals in managing pediatric CRPS. However, it is crucial to recognize that although the symptom pictures may overlap, true (ie, properly diagnosed) CRPS should not be presumed to be a conversion reaction or other psychosomatic disorder but should be viewed as a complex biopsychosocial phenomenon. Consequently, treatment should entail coordinated interdisciplinary efforts that address the biological, physical and psychosocial aspects and sequelae of this complex condition.

The findings of the present study must be evaluated in light of several limitations. First, the study was retrospective and cross-sectional in design. The tertiary clinic-based sample may not be fully representative of the larger population of all children who experience chronic pain. The study is further limited by reliance on self-report assessments of psychological functioning at a single time point, which may be open to social desirability influences, particularly in the setting of a first-time clinical evaluation (43). Although children with CRPS were classified using specific diagnostic criteria, inclusion in the comparison groups did not require adherence to strict diagnostic criteria; therefore, the comparison groups may represent heterogenous conditions with a shared pain location. Finally, it is important to highlight that the diagnostic criteria for CRPS were developed for adult patient populations and were applied to a pediatric sample in the present study because no pediatric criteria have been developed. These criteria may be overly stringent for use with children.

Further work is needed to advance our understanding of pediatric CRPS. Prospective longitudinal studies, particularly those that capture a wide sample of children before some develop CRPS, could provide valuable additional insight into the interplay and causal relations of psychological and biological influences on the condition over time. Future studies should include multiple methods of assessing psychological, behavioural and physical functioning both within the child with pain and in the systems (family, school, etc) comprising the child's environment.

Clinically, much remains unknown regarding this complex chronic pain condition. However, it is hoped that studies such as this will lead to the thorough and accurate assessment and treatment of CRPS by clarifying to medical and mental health practitioners alike that CRPS is a complex chronic pain experience, the maintenance and expression of which are influenced by many individual and environmental factors. Careful diagnosis and evaluation of children with symptoms of CRPS and the provision of treatments to address the multiple biopsychosocial facets of this complex condition are crucial tasks facing pediatric psychologists and other health care providers who encounter this challenging pain condition.

ACKNOWLEDGEMENTS: The authors thank Susan Sager MD, David Leslie MD, Elizabeth Carpino MA and Christina Kyriakos for valuable assistance with the present study; Carl Von Baeyer for helpful feedback on earlier drafts of the manuscript; the Sara Page Mayo Endowment for Pediatric Pain Research and Treatment at Children's Hospital Boston (to $\mathrm{CBB}$ ), and the CHB Department of Anesthesia, Perioperative and Pain Medicine for supporting this work.

\section{REFERENCES}

1. Merskey H, Bogduk N, eds. Classification of chronic pain: Descriptions of chronic pain syndromes and definitions of pain terms. Seattle: IASP Press, 1994.

2. Harden RN, Bruehl S, Perez RS, et al. Validation of proposed diagnostic criteria (the "Budapest Criteria") for complex regional pain syndrome. Pain 2010;150:268-74.

3. Harden RN, Bruehl S, Stanton-Hicks M, Wilson PR. Proposed new diagnostic criteria for complex regional pain syndrome. Pain Med 2007;8:326-31.

4. Bruehl S, Chung OY. How common is complex regional pain syndrome-Type I? Pain 2007;129:1-2.

5. Tan EC, Zijlstra B, Essink ML, Goris RJ, Severijnen RS. Complex regional pain syndrome type I in children. Acta Paediatr 2008;97:875-9.

6. Low AK, Ward K, Wines AP. Pediatric complex regional pain syndrome. J Pediatr Orthop 2007;27:567-72. 
7. Wilder R, Berde C, Wolohan M, Vieyra M, Masek B, Micheli L. Reflex sympathetic dystrophy in children. Clinical characteristics and follow-up of seventy patients. J Bone Joint Surg 1992;74:910-9.

8. Guler-Uysal F, Basaran S, Geertzen JH, Goncu K. A 2 1/2-year-old girl with reflex sympathetic dystrophy syndrome (CRPS type I): Case report. Clin Rehabil 2003;17:224-7.

9. Bruehl S. Comprehensive pain programs: A treatment approach worth validating. J Pain 2006;7:794-6.

10. Bruehl S, Carlson CR. Predisposing psychological factors in the development of reflex sympathetic dystrophy. A review of the empirical evidence. Clin J Pain 1992;8:287-99.

11. Feliu MH, Edwards CL. Psychologic factors in the development of complex regional pain syndrome: History, myth, and evidence. Clin J Pain 2011;26:258-63.

12. Dorsel TN. Chronic pain behavior pattern: A simple theoretical framework for health-care providers. Psychol Rep 1989;65(3 Pt 1):783-6.

13. Egle UT, Hoffmann SO. Psychosomatic correlations of sympathetic reflex dystrophy (Sudeck's disease). Review of the literature and initial clinical results. Psychother Psychosom Med Psychol 1990;40:123-35.

14. Gainer MJ. Somatization of dissociated traumatic memories in a case of reflex sympathetic dystrophy. Am J Clin Hypn 1993;36:124-31.

15. Lynch ME. Psychological aspects of reflex sympathetic dystrophy: A review of the adult and paediatric literature. Pain 1992;49:337-47.

16. Rauis AL. Psychological aspects. A series of 104 posttraumatic cases of reflex sympathetic dystrophy. Acta Orthop Belg 1999;65:86-90.

17. Van Houdenhove B. Prevalence and psychodynamic interpretation of premorbid hyperactivity in patients with chronic pain. Psychother Psychosom 1986;45:195-200.

18. Bruehl S, Husfeldt B, Lubenow TR, Nath H, Ivankovich AD. Psychological differences between reflex sympathetic dystrophy and non-RSD chronic pain patients. Pain 1996;67:107-14.

19. Ciccone DS, Bandilla E, Wu W. Psychological dysfunction in patients with reflex sympathetic dystrophy. Pain 1997;71:323-33.

20. DeGood D, Cundiff G, Adams L, Shutty M, Jr. A psychosocial and behavioral comparison of reflex sympathetic dystrophy, low back pain, and headache patients. Pain 1993;54:317-22.

21. Henson P, Bruehl S. Complex regional pain syndrome: State of the art update. Curr Treat Options Cardiovasc Med 2010;12:156-67.

22. Cruz N, O'Reilly J, Slomine BS, Salorio CF. Emotional and neuropsychological profiles of children with complex regional pain syndrome type-I in an inpatient rehabilitation setting. Clin J Pain 2011;27:27-34.

23. Gatchel R, Peng Y, Peters M, Fuchs P, Turk D. The biopsychosocial approach to chronic pain: Scientific advances and future directions. Psychol Bull 2007;133:581-624.

24. Wilder RT. Management of pediatric patients with complex regional pain syndrome. Clin J Pain 2006;22:443-8.

25. Cimaz R, Matucci-Cerinic M, Zulian F, Falcini F. Reflex sympathetic dystrophy in children. J Child Neurol 1999;14:363-7.

26. Herregods P, Willems J, Chappel R. Pseudodystrophy at the lower limb in children. Clin Rheumatol 1997;16:425-8.

27. Jaworowski S, Allen RC, Finkelstein E. Reflex sympathetic dystrophy in a 12-year-old twin with comorbid conversion disorder in both twins. J Paediatr Child Health 1998;34:581-3.

28. Karakaya I, Coskun A, Agaoglu B, Iseri P, Inanir M, Canatay H. Psychiatric approach in the treatment of reflex sympathetic dystrophy in an adolescent girl: A case report. Turk J Pediatr 2006;48:369-72.

29. Pearson RD, Bailey J. Complex regional pain syndrome in an 8-year-old female with emotional stress during deployment of a family member. Mil Med 2011;176:876-8.

30. Silber TJ. Anorexia nervosa and reflex sympathetic dystrophy syndrome. Psychosomatics 1989;30:108-11.

31. Barbier O, Allington N, Rombouts JJ. Reflex sympathetic dystrophy in children: Review of a clinical series and description of the particularities in children. Acta Orthop Belg 1999;65:91-7.

32. Kachko L, Efrat R, Ben Ami S, Mukamel M, Katz J. Complex regional pain syndromes in children and adolescents. Pediatr Int 2008;50:523-7.

33. Maillard SM, Davies K, Khubchandani R, Woo PM, Murray KJ. Reflex sympathetic dystrophy: A multidisciplinary approach. Arthritis Rheum 2004;51:284-90.
34. Silber TJ, Majd M. Reflex sympathetic dystrophy syndrome in children and adolescents. Report of 18 cases and review of the literature. Am J Dis Child 1988;142:1325-30.

35. Stanton RP, Malcolm JR, Wesdock KA, Singsen BH. Reflex sympathetic dystrophy in children: an orthopedic perspective. Orthopedics 1993;16:773-9; discussion 9-80.

36. Lee BH, Scharff L, Sethna NF, et al. Physical therapy and cognitivebehavioral treatment for complex regional pain syndromes. J Pediatr 2002;141:135-40.

37. Sherry DD, McGuire T, Mellins E, Salmonson K, Wallace CA, Nepom B. Psychosomatic musculoskeletal pain in childhood: Clinical and psychological analyses of 100 children. Pediatrics 1991;88:1093-9.

38. Sherry DD, Wallace CA, Kelley C, Kidder M, Sapp L. Short- and long-term outcomes of children with complex regional pain syndrome type I treated with exercise therapy. Clin J Pain 1999;15:218-23.

39. Sherry DD, Weisman R. Psychologic aspects of childhood reflex neurovascular dystrophy. Pediatrics 1988;81:572-8.

40. Walker LS, Greene JW. Children with recurrent abdominal pain and their parents: More somatic complaints, anxiety, and depression that other patient families? J Pediatr Psychol 1989;14:231-43.

41. Huguet A, Miro J. The severity of chronic pediatric pain: An epidemiological study. J Pain 2008;9:226-36.

42. Claar RL, Baber KF, Simons LE, Logan DE, Walker LS. Pain coping profiles in adolescents with chronic pain. Pain 2008;140:368-75.

43. Logan DE, Claar RL, Scharff L. Social desirability response bias and self-report of psychological distress in pediatric chronic pain patients. Pain 2008;136:366-72.

44. Bruehl S, Harden RN, Galer BS, et al. External validation of IASP diagnostic criteria for complex regional pain syndrome and proposed research diagnostic criteria. International Association for the Study of Pain. Pain 1999;81:147-54.

45. von Baeyer CL, Spagrud LJ, McCormick JC, Choo E, Neville K, Connelly MA. Three new datasets supporting use of the Numerical Rating Scale (NRS-11) for children's self-reports of pain intensity. Pain 2009;143:223-7.

46. Claar RL, Walker LS. Functional assessment of pediatric pain patients: Psychometric properties of the functional disability inventory. Pain 2006;121:77-84.

47. Walker LS, Greene JW. The functional disability inventory: Measuring a neglected dimension of child health status. J Pediatr Psychol 1991;16:39-58.

48. Walker LS, Garber J, Greene JW. Somatization symptoms in pediatric abdominal pain patients: Relation to chronicity of abdominal pain and parent somatization. J Abnorm Child Psychol 1991;19:379-94.

49. Kovacs M. The Children's Depression Inventory (CDI). Psychopharmacol Bull 1985;21:995-8.

50. Kovacs M. Children's Depression Inventory Manual: North Tanawanda, NY: Multi-Health Systems, 1992.

51. Reynolds CR, Richmond BO. What I think and feel: A revised measure of children's manifest anxiety. J Abnorm Child Psychol 1978;6:271-80.

52. Walker LS, Smith CA, Garber J, Van Slyke DA. Development and validation of the pain response inventory for children. Psychol Assess 1997;9:392-405.

53. Cohen J. Statistical power analysis for the behavioral sciences. New York: Erlbaum, 1998.

54. Meier PM, Alexander ME, Sethna NF, et al. Complex regional pain syndromes in children and adolescents: Regional and systemic signs and symptoms and hemodynamic response to tilt table testing. Clin J Pain 2006;22:399-406.

55. Bruehl S. An update on the pathophysiology of complex regional pain syndrome. Anesthesiology 2010;113:713-25

56. Feldman SI, Downey G, Schaffer-Neitz R. Pain, negative mood, and perceived support in chronic pain patients: A daily diary study of people with reflex sympathetic dystrophy syndrome. J Consult Clin Psychol 1999;67:776-85.

57. Geha PY, Baliki MN, Harden RN, Bauer WR, Parrish TB, Apkarian AV. The brain in chronic CRPS pain: Abnormal graywhite matter interactions in emotional and autonomic regions. Neuron 2008;60:570-81. 


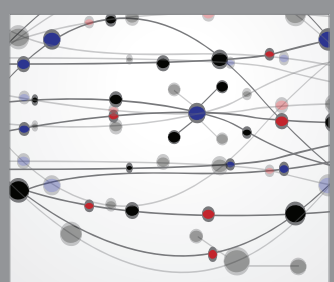

The Scientific World Journal
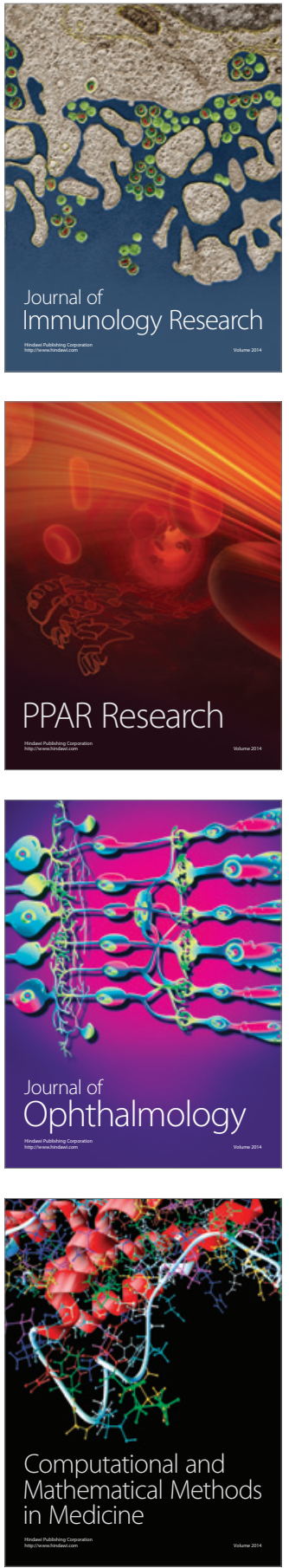

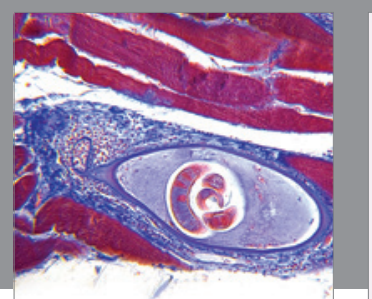

Gastroenterology Research and Practice

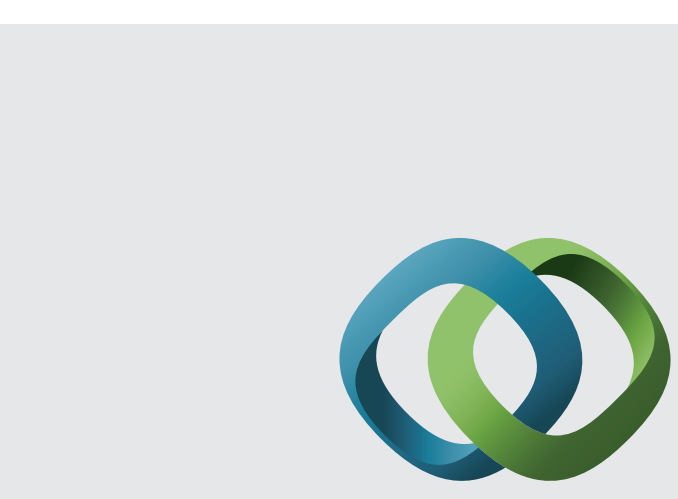

\section{Hindawi}

Submit your manuscripts at

http://www.hindawi.com
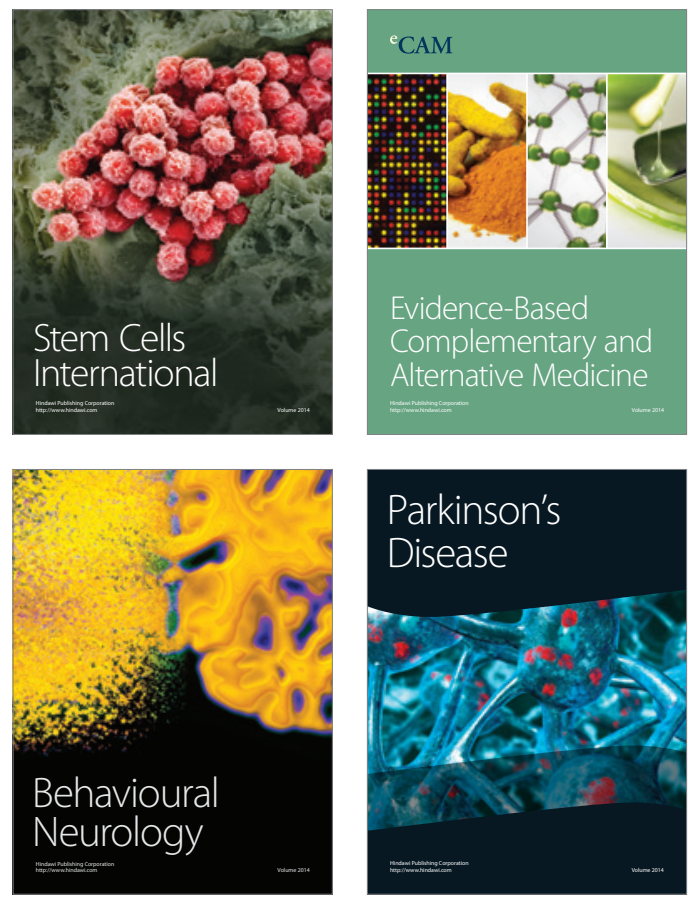
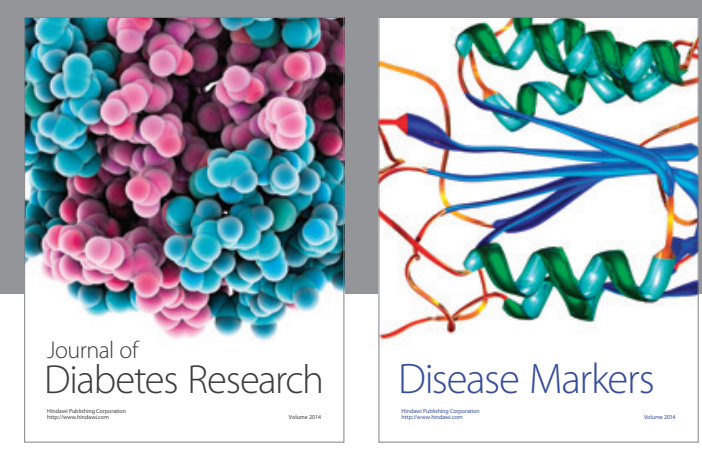

Disease Markers
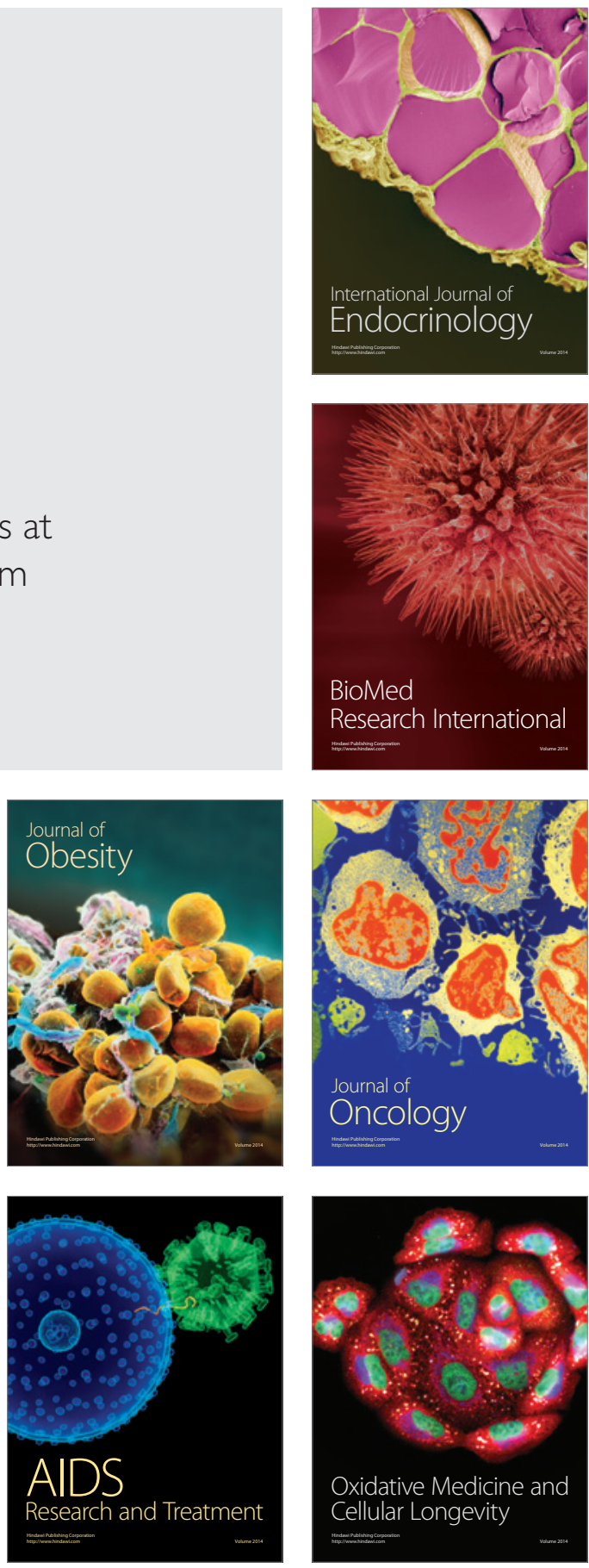